\title{
HOSPITAL WASTE MANAGEMENT AS A POTENTIAL HAZARD IN SELECTED PRIMARY HEALTHCARE CENTRES IN ZARIA, NIGERIA
}

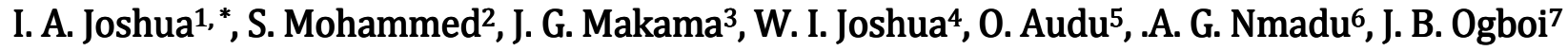 \\ 1,6 DePARTMent of Community Medicine, Kaduna STATE University, Kaduna, NIGERIA \\ ${ }^{2}$ Centre For Disaster Risk Management and Development Studies, Ahmadu Bello University, Zaria, NigERIA \\ 3 DEPARTMENT OF SURgery, AHMAdU BELlo UnivERSITY TEACHING HOSPITAL, ZARIA, NIGERIA \\ ${ }^{4}$ CEnTRal Procurement Unit, AhMAdu BELlo University, ZARIA, NIGERIA \\ 5 Dept of Epidemiology And Community Health, Coll. of Health Sciences, Benue STAte Univ. MaKuRdi, Nigeria \\ 7 Dept of Experimental Medicine and Public Health, University Of Camerino, 62032 Camerino (Mc), italy \\ E-mail addresses: ${ }^{1}$ dristifanus@yahoo.com, 2 msambo40@yahoo.com, ${ }^{3}$ jerlizabeth@yahoo.com, \\ 4ask4watuski@yahoo.com,5audeeony@yahoo.com,6 jumainmadu@yahoo.com,7ogboijb@yahoo.com
}

\begin{abstract}
The operations of health facilities generate waste; a common characteristic of hospitals and Primary Healthcare centres. However, improper handling of hospital waste constitutes potential risks to the environment and human health. Unfortunately, hospital waste management is not yet carried out with a satisfactory level of safety in many parts of the globe, especially in the underdeveloped world. This study was carried out with the aim of assessing hospital waste management practices among selected Primary Healthcare Centres (PHCs) in Zaria, Nigeria. A cross sectional descriptive study was carried out between October 2012 and March, 2013 using staff of the PHCs and an interviewer-administered questionnaire, checklist and participant observations. Majority of the staff of the PHCs were nurses (37\%) and the knowledge score of all the staff was 5 out of 10 (50\%). About $73 \%$ had training on hospital waste management $31 \%$ had reported injury by sharps. Also, 66\% use protective hand gloves while doing their work. Wheel barrow was the commonest method of transporting waste and open burning was the final method of waste disposal by the PHCs. There is a need for safer means of waste disposal among the medical facilities visited. It was, therefore, recommended among others that funds should be made available to the PHCs. This is to ensure the acquisition of all facilities needed in hospital waste management and disposal. There should be training and re-training of health staff on current hospital waste management to meet global best practices.
\end{abstract}

Keywords: Hospital waste, Potential Hazard, Primary Health Care Centres, Zaria

\section{INTRODUCTION}

Hospitals are health institutions providing preventive, promotive and or curative care services. This may directly be through patient care or indirectly by ensuring a clean, healthy environment for their employees and the community [1]. Hospital waste is referred to as waste, solid and liquid from healthcare establishment, research facilities, and laboratories, blood banks, nursing homes, mortuaries, autopsy centres. They could be classified into hazardous (such as infectious, pharmaceuticals, sharps, chemical, radioactive and heavy) and non-hazardous (such as paper, packaging, debris) [2].

High income and low income countries generate on average $0.5 \mathrm{~kg} / \mathrm{bed} /$ day and $0.2 \mathrm{~kg} / \mathrm{bed} /$ day of hazardous hospital wastes respectively [3]. Globally, the amount of hospital waste generated was projected to double by the year 2000 and quadruple by year 2025 [4]. Advances in medical facilities with the introduction of sophisticated instruments have increased the waste generation per patient in health care units [5]. A survey, conducted by World Health Organisation (WHO), to assess hospital waste management in 22 developing countries, showed that the proportion of inappropriate waste disposal methods was between 18 and 64\% [6]. The stringent environmental control and legislation on hospital waste in the United Kingdom (UK) has ensured high standards of waste disposal but failed to reduce the amount of the hospital waste generated in the UK [7].

\footnotetext{
* Corresponding author
} 
Poor management of hospital waste is known to contribute to spread of nosocomial infections [8]. WHO has estimated that, in each year, there are 8-16 million cases of hepatitis B Virus infection. Also, 2.34.7 million cases of hepatitis C Virus infection and 80,000-160,000 cases of HIV due to unsafe injections and mostly due to unusually poor hospital waste management systems [6]. Unregulated clinical waste treatment and disposal has been linked to various public health threats [9]. Harmful chemicals present in these wastes such as heavy metals can also cause water pollution.

Landfill technology can also cause water pollution in the form of leachates. The illegal dumping of medical wastes in deprived residential areas has resulted in situations where children have been found playing with medical waste materials such as used syringes [10].

Burning and incineration of medical and municipal waste have resulted in the release of toxic dioxin as well as mercury and other toxic substances. These substances create a remarkable variety of adverse effects in Human at extremely low doses [6]. The objective of this paper is to assess knowledge and practices of hospital waste management among staff of selected Primary Healthcare Centres (PHCs) in Zaria, Nigeria.

\section{MATERIALS AND METHODS}

\subsection{Study Area}

Zaria is a large, heterogeneous city with a population of about 1.490,000 persons from different parts of the world. It is second in size only to the State capital, Kaduna. It is located on the high plains of Northern Nigeria, 652.6 metres above the sea level, some $950 \mathrm{~km}$ away from the coast [11].

Zaria currently has 64 health care facilities consisting of 21 primary health centres, 42 health clinics and 1 health post yet to be commissioned. These health facilities are distributed within the 24 wards in Zaria. These Wards include Bomo, Jama'a, Hanwa, Jushi, UngwanGabas, Chikaji, Muchiya, Dogarawa, Zabi, Basawa, Samaru, Wuciciri, Dambo, Kufena, TukurTukur, Tudun-Wada, Dusten Abba, Kwarbai [A], Kwarbai [B], Limanchin Kona, Gyallesu, Kaura, UnguwanFatika and UnguwanJuma. In addition, there are a total of 51 registered private clinics and hospitals and 12 clinics belonging to allied industries or training institutions. Numerous patent medicine vendors and chemists and traditional medical practitioners also exist and are well patronized by the people. Ahmadu Bello Teaching Hospital located less than $3 \mathrm{~km}$ from Samaru serves as the main tertiary health referral centre for the other health care facilities.

\subsection{Study design, sampling technique, sample size and study population}

It was a cross sectional descriptive study, carried out between October 2012 and March 2013. The study assessed the knowledge and practices of staff of the selected PHCs in Zaria associated with hospital waste management as a potential hazard.

Multi-staged sampling technique was employed. Within the 24 wards, a total of ten PHCs were randomly selected (one PHC from every ward) The selected PHCs were those of Hanwa, Chikaji, Muchiya, Samaru, Gyallesu, Tuku-Tukur, Tudun Wada, Unguwan Alkali (KwarbaiB, Zango and Pallandan Selection of the respondents was done via random sampling with the list of health care providers in the selected health facilities as sampling frame. The study populations were the 100 staff of the 10 selected PHCs that willingly participated in the study.

\subsection{Data collection tools}

The respondents were assessed using an interviewer administered, semi-structured questionnaire, checklist and participants observation. The tools were pretested at Rahama and AngwanBawa PHCs in Soba and Saminaka Local Government Areas of Kaduna State respectively. This was done to fine turn the data collection tools.

\subsection{Data Analysis}

The data collected were checked for completeness, cleaned, coded and entered into Statistical Package for Social Sciences (SPSS) version 17 software. The data was summarized and presented in tables and charts. The knowledge was scored using the variable listed in table 2 . Any yes or fully correct response has 1 point and no or incorrect response has zero point. Partially correct response has half $(1 / 2)$ point. The adopted grading system for the score of the knowledge is as follow: $7-10$ points $=$ excellent, $5-6=$ average and 0 $-4=$ poor. The total maximum point per respondent is 10 points.

\subsection{Ethical consideration}

Ethical approval was obtained from the Ethical Committee of Kaduna State Ministry of Health. The 
aim of the study was explained to the respondents after which their consent was obtained. They were also informed that their participation in the research is voluntary and no names needed.

\section{RESULTS AND DISCUSSION}

\subsection{Results}

Majority of the respondents were nurses (37\%), followed by midwives (Figure 2).

The PHCs have 2-5 departments, and the mean number of beds, outpatients and inpatients seen per day per PHC were 6, 30 and 4 respectively (Table 1).

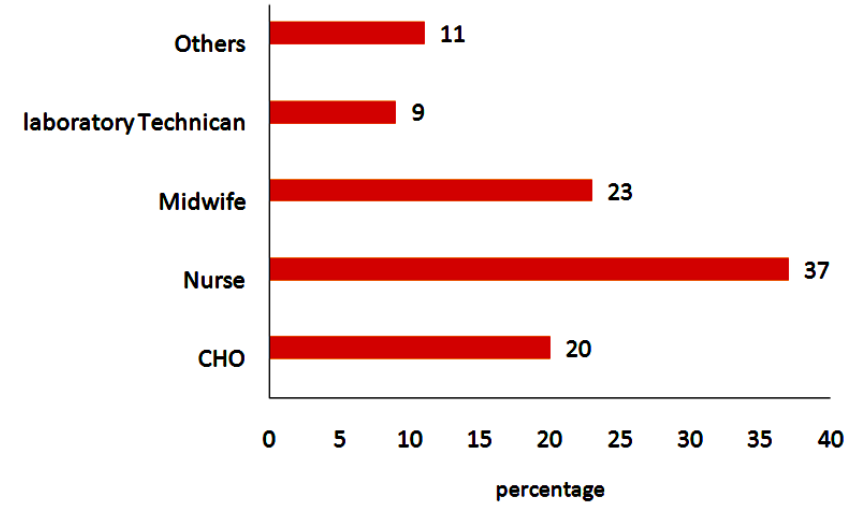

Key: CHO - Community Health Officer

Figure 2: Cadre of staff at the PHCs

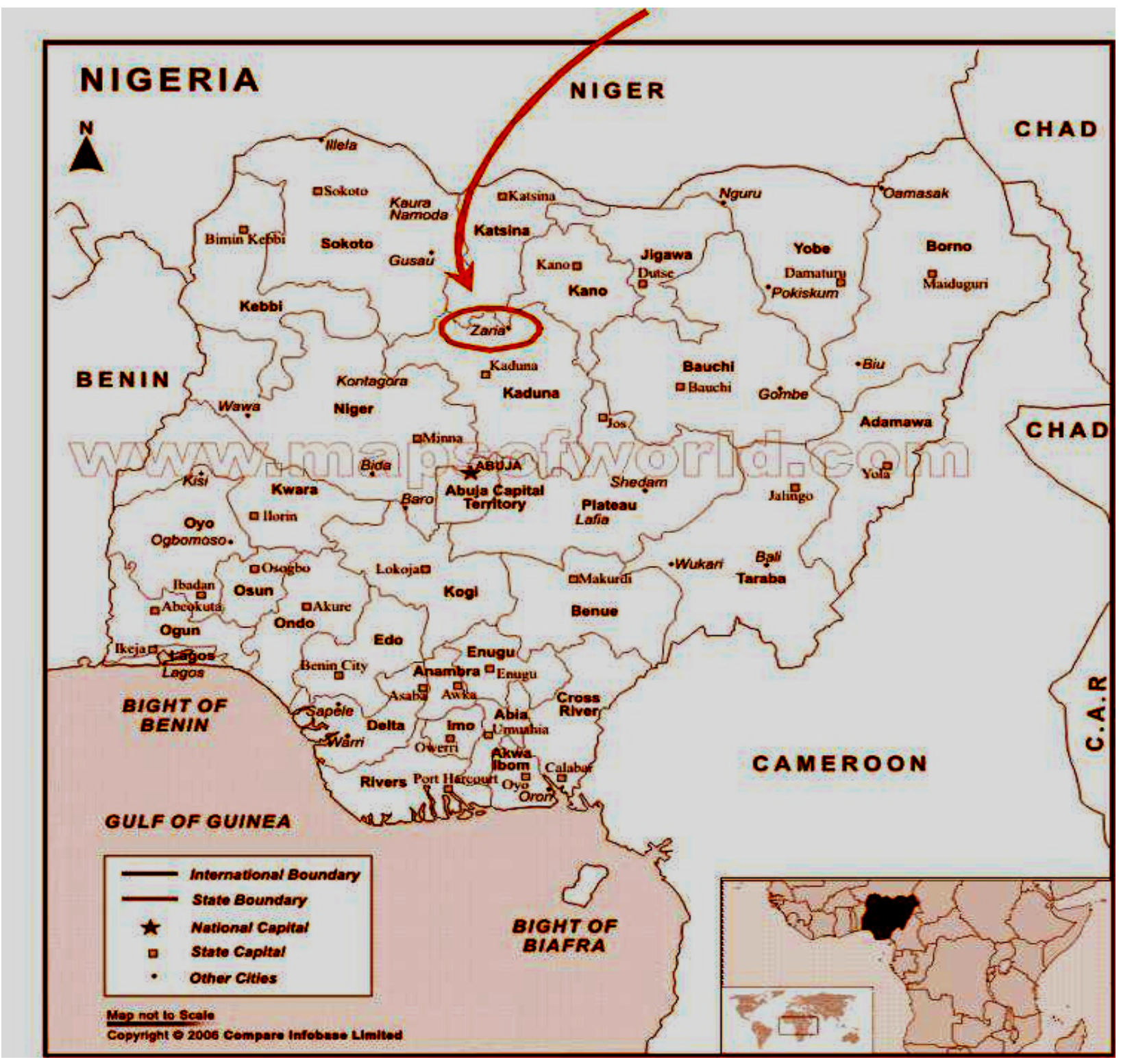

Figure 1: Map of Nigeria showing Zaria in Kaduna State 
Table 1: Summary of Resources in the selected PHCs

\begin{tabular}{ll}
\hline Variables & Statistics \\
\hline Name of PHC & No of depts \\
PHC Hanwa & 4.0 \\
PHC Chikaji & 4.0 \\
PHC Muchiya & 3.0 \\
PHC Samaru & 3.0 \\
PHC Tuku-Tukur & 3.0 \\
PHC Tudun Wada & 5.0 \\
PHC Unguwan Alkali (Kwarbai B) & 3.0 \\
PHC Gyallesu & 3.0 \\
PHC Zango & 2.0 \\
PHC Pallandan & 2.0 \\
\hline Number of Beds in the PHCs & Frequency \\
Mean & 6.0 \\
Minimum & 2.0 \\
Maximum & 11.0 \\
Standard deviation (SD) & 3.19 \\
\hline No. of Out-Patients Seen Per Day in the & Frequency \\
PHCs & \\
Mean & 30.0 \\
Minimum & 18.0 \\
Maximum & 43.0 \\
SD & 8.49 \\
\hline Number of In-Patients Seen Per Day in & Frequency \\
the PHCs & \\
Mean & 4.0 \\
Minimum & 2.0 \\
Maximum & 7.0 \\
SD & 1.55 \\
\hline
\end{tabular}

About half (51\%) and $78 \%$ of the respondents had knowledge about hospital waste policy and its management plan respectively. $31 \%$ and $20 \%$ had fully correct knowledge of types and components of hospital waste management respectively.

High percentages ( $86 \%$ and $92 \%$ ) of the respondents had incorrect knowledge of segregation of hospital waste and color coding of hospital waste management respectively. Half (50\%) had fully correct knowledge of use of safety box, but only $22 \%$ and $40 \%$ had fully correct knowledge of mode of treatment of hospital waste before disposal and the proper methods of final disposal of hospital waste respectively. Total of $65 \%$ of the respondents had partial to fully correct knowledge of health hazards associated with poor hospital waste management. The mean score for the knowledge of hospital waste management by the staff of the PHCs is $50 \%$ (5 points out of 10 ) (Table 2 ).
Table 2: Knowledge of hospital waste management by the staff of the selected PHCs in Zaria $(n=100)$

\begin{tabular}{lll}
\hline Variable & Frequency & Percentage \\
\hline Knowledge of Hospital waste Policy & & \\
Yes & 51 & 51.0 \\
No & 37 & 37.0 \\
Do not know & 12 & 12.0 \\
\hline Knowledge of hospital & waste & \\
management plan & & \\
Yes & 78 & 78.0 \\
No & 9 & 9.0 \\
Do not know & 13 & 13.0 \\
\hline
\end{tabular}

Knowledge of types of hospital waste

Fully correct $\quad 31 \quad 31.0$

Partially correct $\quad 19 \quad 19.0$

$\begin{array}{lll}\text { Incorrect } & 50 & 50.0\end{array}$

Knowledge of components of hospital waste management

$\begin{array}{lll}\text { Fully correct } & 20 & 20.0\end{array}$

Partially correct $\quad 15 \quad 15.0$

$\begin{array}{lll}\text { Incorrect } & 65 & 65.0\end{array}$

Knowledge of segregation of

Hospital waste into categories

Fully correct $\quad 4 \quad 4.0$

Partially correct $\quad 10 \quad 10.0$

$\begin{array}{lll}\text { Incorrect } & 86 & 86.0\end{array}$

Knowledge of color coding of hospital waste

Fully correct $\quad 4 \quad 4.0$

Partially correct $\quad 4 \quad 4.0$

$\begin{array}{lll}\text { Incorrect } & 92 & 92.0\end{array}$

Knowledge of use of safety box

Fully correct $\quad 50 \quad 50.0$

Partially correct $\quad 39 \quad 39.0$

Incorrect $11 \quad 11.0$

Knowledge of mode of treatment of

hospital waste before final disposal

\begin{tabular}{lll} 
Fully correct & 22 & 22.0 \\
Partially correct & 20 & 20.0 \\
Incorrect & 58 & 58.0 \\
\hline
\end{tabular}

Knowledge of appropriate methods

of final disposal of hospital waste

Fully correct $\quad 40 \quad 40.0$

Partially correct $\quad 28 \quad 28.0$

$\begin{array}{lll}\text { Incorrect } & 32 & 32.0\end{array}$

Knowledge of health hazards

associated with poor hospital waste

management

$\begin{array}{lll}\text { Fully correct } & 35 & 35.0\end{array}$

Partially correct $\quad 30 \quad 30.0$

Incorrect $35 \quad 35.0$

Mean score of knowledge is 5 out of 10 points (50\%) (Calculated from Table 2)

More than two-third (73\%) of the respondents had training on hospital waste management and $32 \%$ practice hand washing with soap and water as a 
universal precaution. Thirty -one (31) percent reported that they had ever sustained injury by sharps, out of which only 11 staff (35.5\%) thoroughly washed the injury sites with soap and water (Table 3).

Table 3: Practices of hospital waste management by the staff of the PHCs

\begin{tabular}{lll}
\hline Variable & Frequency & Percentage \\
\hline $\begin{array}{l}\text { Staff receiving training on } \\
\text { hospital waste management }\end{array}$ & & \\
Yes & 73 & 73.0 \\
No & 27 & 27.0 \\
\hline $\begin{array}{l}\text { Practice of hand washing by } \\
\text { the staff }\end{array}$ & \\
Yes & 32 & 32.0 \\
No & 68 & 68.0 \\
\hline $\begin{array}{l}\text { Sustaining injury by sharps by } \\
\text { the staff as a universal }\end{array}$ & \\
precaution & \\
Yes & 31 & 31.0 \\
No & 69 & 69.0 \\
\hline $\begin{array}{l}\text { Immediate measures taken } \\
\text { after sustaining injury by } \\
\text { sharps (n=31) }\end{array}$ \\
$\begin{array}{l}\text { Nothing was done } \\
\text { Thorough washing of the } \\
\text { injury with soap and water }\end{array}$ \\
\hline
\end{tabular}

However, all (100\%) of the PHCs do not practice color coding of waste management. Two of the PHCs were physically seen using safety box by the staff. In 5 PHCs, wastes are usually kept for 12 - 24hours within the premises before it is finally disposed of. Only one of the PHCs (10\%) treats its waste before final disposal by open burning (80\%). The commonest method of treatment of hospital waste available was by incineration (90\%) (Table 4).

Two third (66\%) of the respondents use protective gloves while doing their work such as handling of some patients, washing of instruments, collection and disposal of waste, cleaning of the PHCs, among others (Figure 3).

Wheel barrow is the commonest form of transportation (50\%) of hospital waste in the PHCs (Figure 4).

\subsection{Discussion}

Majority of the staff in the PHCs were nurses, followed by midwives. The departments in the PHCs range between 2 and 5 with PHC Tudunwada having 5 departments and the highest number of 11beds; PHC Samaru has the largest number of 43 outpatients and 7 inpatients seen daily (Table 1).

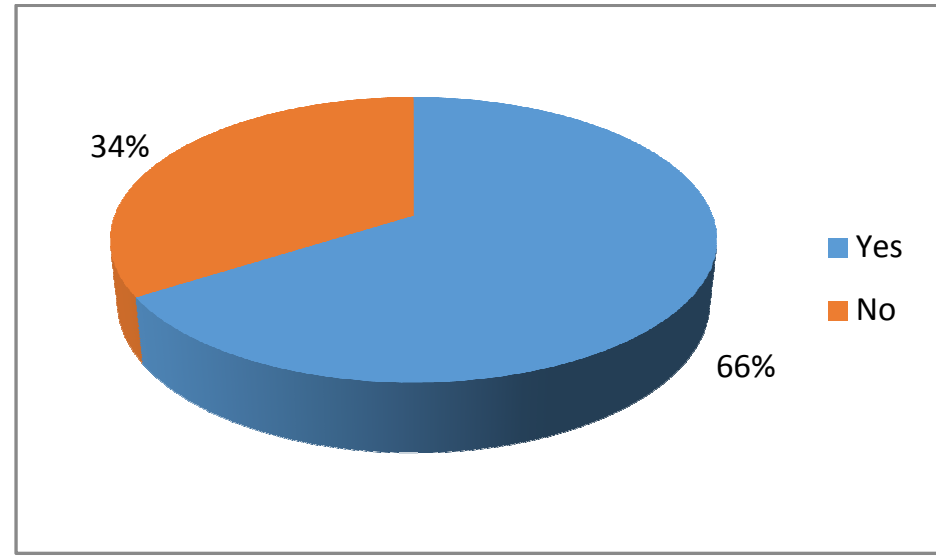

Figure 3: Use of Protective Gloves by Staff

Table 4: Some practices and facilities in the PHCs $(n=10)$

\begin{tabular}{|c|c|c|}
\hline Variable & Frequency & Percentage \\
\hline \multicolumn{3}{|c|}{$\begin{array}{l}\text { Practice of colour coding in } \\
\text { the PHCs }\end{array}$} \\
\hline Yes & - & - \\
\hline No & 10 & 100.0 \\
\hline \multicolumn{3}{|c|}{$\begin{array}{l}\text { Availability of safety boxes in } \\
\text { the PHCs }\end{array}$} \\
\hline Yes & 2 & 20.0 \\
\hline No & 8 & 80.0 \\
\hline \multicolumn{3}{|c|}{$\begin{array}{l}\text { Duration of storage of waste } \\
\text { on-site }\end{array}$} \\
\hline$<12$ hours & 1 & 10.0 \\
\hline $12-48$ hours & 5 & 50.0 \\
\hline$>48$ hours & 4 & 40.0 \\
\hline \multicolumn{3}{|c|}{$\begin{array}{l}\text { Treatment of Hospital Waste } \\
\text { prior to disposal }\end{array}$} \\
\hline Yes & 1 & 10.0 \\
\hline No & 9 & 90.0 \\
\hline \multicolumn{3}{|c|}{$\begin{array}{l}\text { Method of Treatment of } \\
\text { Hospital waste available }\end{array}$} \\
\hline Incineration & 9 & 90.0 \\
\hline Others & 1 & 10.0 \\
\hline \multicolumn{3}{|c|}{$\begin{array}{l}\text { Methods of Final disposal of } \\
\text { hospital waste adopted }\end{array}$} \\
\hline Open dumping & 2 & 20.0 \\
\hline Open burning & 8 & 80.0 \\
\hline
\end{tabular}

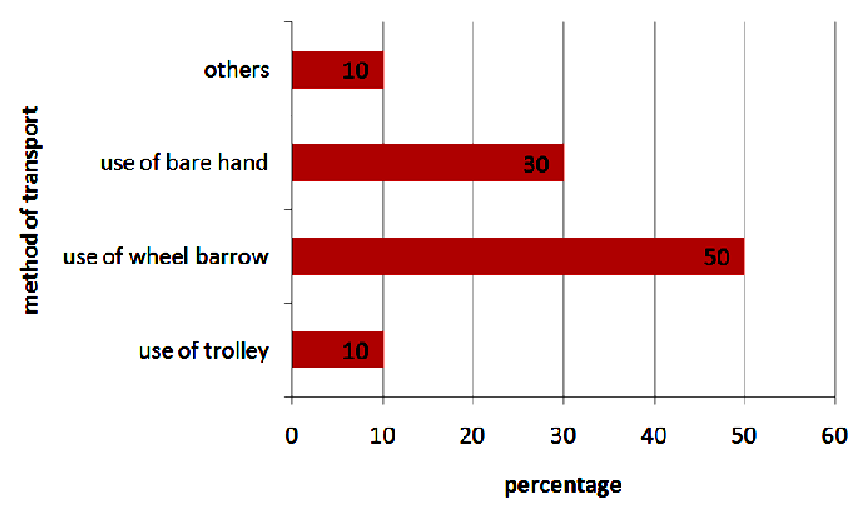

Figure 4: Methods of transportation of hospital waste

About half of the respondents were aware of the existence of healthcare waste management policy. Coker et al found that ${ }_{2}$ though ${ }_{2}$ there is healthcare waste management policy, majority of the health care workers, were not aware of it while others just wish it 
away [12]. They noted that the neglect of healthcare waste management policies by health workers is detrimental to the health of those they are meant to protect.

A good percentage (78\%) of the healthcare workers had knowledge of healthcare waste management plan. These 2 parameters (healthcare waste policy and plan) could help them in their daily activities as it relates to healthcare waste management and hence the reduction of the potential hazards. A study revealed that healthcare workers inwaste management units are properly kept aware of waste management plans which could assist the performance of their daily duties [13]. They also noted that $_{2}$ in most third world countries ${ }_{2}$ these plans are rarely made clear to the workers, thereby militating against hygiene in the healthcare facilities.

A very significant percent of the staff had incorrect knowledge of types, components and segregation of hospital waste. Also, knowledge of colour coding of hospital waste was incorrect; all these could reflect in their practices. Knowledge of the use of safety box was average, however, the knowledge of the mode of treatment of hospital waste before final disposal and appropriate methods of final disposal of hospital waste were not consistent with the high percentage (73\%) of the staff that had training on hospital waste management. The implication of this is that there may be need to revise the training programme for the staff. Training in healthcare waste management is a vital aspect of healthcare management. This helps to improve knowledge of the workers [14], even though sometimes the knowledge does not translates into positive practices. The practice of hand washing with soap and water is a component of universal precaution which is essential in the protection of staff and patients in the spread of nosocomial infections. Injury by sharps is a common practice in health care settings. Of the 31 (31\%) of the staff that had injury by sharps only $11(35.5 \%)$ of them actually washed the injury sites thoroughly with soap and water. None among this group of staff was given post exposure prophylaxis against HIV/AIDS. This could be as a result of lack of adequate knowledge on the protocol or guidelines.

None of the PHC workers practices color coding in the segregation of their healthcare waste.This finding is similar to that of Al-Khatib et al [15].This is a critical component that is in line with global best practices. This ensures the disposal of healthcare waste and allowed for the recycling of some waste for other uses.
Sharps are dangerous healthcare waste that play role in the transmission of infectious agents. A good number of the staff of the PHCs disposes sharps in safety boxes. A study showed that sharps safety boxes are essential components of storage of sharps in healthcare facilities as they constitute health risks inthe healthcare environment [16]. The duration of temporary storage of the hospital waste within the PHCs for $12-48$ hours before final disposal is in line with best international practices.

Over $90 \%$ of the PHCs do not treat their healthcare waste before final disposal due to lack of facilities such as necessary chemical for disinfection and autoclave. The small percentage that said that they treat their healthcare waste before disposal use open burning usually in a pit as the method of treatment. This is because the process is inexpensive and more convenient. However, the hot ashes can serve as a health hazard especially if it is not properly done. A similar study posited that treatment of healthcare waste before disposal or use of scientific methods of disposal are largely lacking in Nigeria as other developing countries due to lack of the fund to acquire the needed facilities [17].

Over $80 \%$ of the PHCs practices open burning of their healthcare waste as the final method of disposal because it is extremely cheap and cost effective. However, if this is not properly done it could have adverse public health consequences. The remnant ashes left could accumulate and serve as waste that needed to be disposed also ${ }_{i}$ the non-combustible waste materials needed to be disposed by other way and also the burning process could serve as a source of fire that could result in fire outbreaks among others. Hence, educating the staff responsible for the burning process of the healthcare waste is extremely valuable.

The practice of the use of personal protective equipment especially hand gloves was observed by $66 \%$ of the staff, however, their use by the staff may not be consistent. This is especially useful in the protection of the staff working in the PHCs; $_{2}$ therefore enforcement by the heads of the various PHCs is required to improve compliance. The final disposal of hospital waste using wheel barrows that usually do not have covers is dangerous and could aid in the spread of infections. However, there are modern dustbins with wheels that could be used for such purpose. 


\section{CONCLUSION}

Health care waste if not properly managed has the potential of posing a serious threat to health and environment. Despite the significant percentages of the staff of the primary health care centres having knowledge on HCW management policy and plan and attending training on HCW management, a good proportion do not practice hand washing, segregation and colour coding. The lack of treatment of waste prior to disposal, use of wheel barrow as means of transportation of HCW and use of open burning as final means of disposal of the HCW among others, there is need for comprehensive HCW management program.

In view of the above, the authors recommend the following as a way forward:

a) There should be adequate training and re-training of the hospital staff on safe waste management and disposal practices by the relevant stakeholders.

b) There is the need to acquire of modern facilities for transportation of hospital waste such as modern trolley and wheel- dustbins by the local government.

c) The Ministry of Health should endeavor to ensure the availability of hand gloves, chemicals and other protective equipment for use by the personnel in the PHCs.

d) Medical workers should be encouraged to report cases of injuries from used sharp objects so that prompt treatment could be instituted.

e) The staff should be trained on universal precaution and proper guideline of management of injury by sharps and post exposure prophylaxis.

\section{REFERENCES}

[1] Patil GV and Pokhrel K. "Biomedical Solid Waste Management in an Indian Hospital: A Case Study". Waste Management, 2005, 25 (3):592-599

[2] Stanley HO, Okpara KE, Chukwujekwu DC, Agbozu IE, Nyenke CU, (2011). Health care waste management in Portharcourt Metropolis. American Journal of Scientific and Industrial Research 2011, 2(5), pp769-773

[3] WHO: Waste from Health Care Activities, WHO fact sheet No 253, www.who.int/media centre/fact sheets/fs 253 (accessed 20th February, 2013)

[4] Akter N. Medical Waste Management: A Review. Environmental Engineering Program, School of environment, Resource and Development and Asian Institute of Technology, Thailand.2005, pp34-39

[5] Orloff K, and Falk H. "An International Perspective on
Hazardous Waste Practices" International Journal of Hygiene and Environmental Health (2003), 206:pp291-302

[6] WHO: "Healthcare Waste Management (HCWM): Healthcare Waste and its Safe Management". 2005 Url:http://www.health care waste. Org/en/115_ overview.html. 2004 Accessed 14/4/201프

[7] Tudor TL, Marsh CL, Butler S, and Van Horn JL. "Realizing Resource Efficiency in theManagement of Health Care Waste from the Cornwall National Health Service (NHS) inUK". Waste Management. 2008, 28(7): pp1209- 1218

[8] Sobotova L, Noscova T, Volekova A and Aghol G. "Practical Training on Nosocomial Infection in a Hospital Environment". Indoor built environ. (2004), 5(1): pp73-76

[9] Solberg KE. "Trade in Medical Waste Causes Deaths in India". The Lancet, 373,2009, pp1067

[10] Reuters News Agency. "Afghanistan Medical Waste Poses Health Risks in Urban Areas" url:http//www.alertnet.org/thenews/newsdesk/IR IN/fbOb02c252900fdl8716034303f6dc c4.htm. 2008 Accessed 13/04/2013

[11] Mortimore, M.J. "Zaria and its region”. Annals of the Association of American Geographers, 1970, 60, pp73-80

[12]Coker A, Sangodoyin A, Sridhar M, Booth C, Olomolaiye P, Hammond F: "Medical Waste Management in Ibadan, Nigeria: Obstacles and Prospects" Journal of Waste Management, 29 (2) (2004): 804-811

[13] Acharya DB and Singh M: The Book of Hospital Waste Management. Minerva Press, New Delhi, 2000, pp15: 47

[14] Mahmood SS, Malik R, and Azim W: A study of Waste Generation, Collection and Disposal in a tertiary hospital in Pakistan. Pakistan Journal of medical research. (2001), 40: 13-17

[15] Al-Khatib IA, Ali-Shtayeh MS, and Al-Qaroot YS: "Management of Healthcare Waste in Circumstances of Limited Resources: A Case Study of PHCs in Iran". Waste Management Research (2005), 27 (3) : 305-312

[16] Manyele SV, and Lyasenga TJ: Factors affecting Medical Waste Management in Low Level Health Facilities in Tanzania, African Journal of Environmental Science and Technology 4 (5) (2010):304-318

[17] Ogbonna DN. "Characteristics and Waste Management Practices of Medical Waste in Health Care Institutions in Port Harcourt, Nigeria". Journal of Soil Science and Environmental Management, 2002, 2(5): pp132-141 